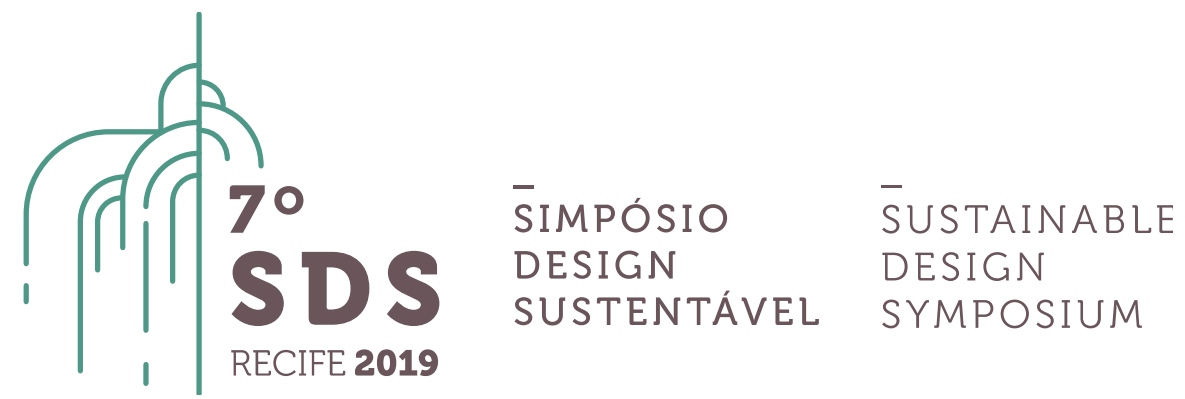

\title{
Sustentabilidade: prática transversal no ensino de design de produto
}

\author{
Itamar Ferreira da Silva ${ }^{1}$, Thamyres Oliveira Clementino ${ }^{2}$ e Letícia Freire Negromonte ${ }^{3}$ \\ ${ }^{1}$ UFCG, Unidade Acadêmica de Design, itamarfs0210@gmail.com \\ ${ }^{2}$ UFCG, Unidade Acadêmica de Design, thamyres.oliveira.clementino@gmail.com \\ ${ }^{3}$ UFCG, Unidade Acadêmica de Design, leticiafnegromonte@gmail.com
}

\begin{abstract}
Resumo. $O$ presente artigo expõe a importância da inserção transversal do conceito de design para a sustentabilidade em cursos de graduação. Objetivou apresentar um método desenvolvido para abordar o conceito de Life Cicle Design no primeiro período do curso de Design de Produto da Universidade Federal de Campina Grande/PB, por meio da disciplina de Projeto 1. Como resultados, são exibidos os produtos desenvolvidos pelos alunos a partir da aplicação do método e as implicações positivas da adoção de estratégias sustentáveis desde o ingresso dos alunos na universidade.
\end{abstract}

Palavras-chave. Ensino transversal; graduação em design; projeto; design para a sustentabilidade; Life cicle design.

\section{Introdução}

O crescimento da problemática ambiental gerou a necessidade de melhorias na relação entre o homem e o meio ambiente, o que fomentou discussões sobre a "sustentabilidade", definida em 1987 no relatório Brundtland da ONU como o desenvolvimento que supre as necessidades atuais sem comprometer as capacidades das gerações futuras suprirem as suas próprias. Para Manzini e Vezzoli (2011), é intrínseca a esta abordagem o desenvolvimento sustentável, que visa superar o modelo de bem-estar baseado no uso excessivo de capital natural, objetivando integrar as ações humanas a resiliência do planeta. Na busca por efetivar este paradigma de desenvolvimento, aspira-se integrar as dimensões ambiental, socioética e econômica e política a fim de revelar o papel de cada uma em prol de um novo modelo de bemestar, que desta vez esteja pautado na coerência entre o consumir e os limites ambientais.

Para impulsionar e viabilizar esta transição é necessário à atuação de vários atores que, segundo Manzini (2008), busquem facilitar o processo. Entre eles encontra-se o designer, que de acordo com Kazazian (2005), tem papel importante para a construção de novas relações entre o meio ambiente e o consumo, apresentando potencial para gerar soluções que não demandem a destruição do meio ambiente, mas sim, a busca por caminhos que conduzam a uma economia "leve", onde haja integração entre as dinâmicas naturais e os produtos produzidos para o homem. 
Isto, de acordo com Manzini (2008), ocorre porque o design apresenta grande potencial para tornar-se parte da solução, já que em seu código genético está registrada a ideia de que sua razão de ser é melhorar a qualidade do mundo.

Mas, para a implementação dos princípios do design para a sustentabilidade com foco na dimensão ambiental ${ }^{\mathrm{a}}$, é necessário a ingressão em níveis progressivos de redução dos impactos ambientais e de alteração na mudança de hábitos e comportamento dos consumidores. Para Sampaio et. al (2018), inicia-se pela busca na melhoria dos fluxos de produção e consumo, passando para o foco no desenvolvimento de produtos por meio do redesign ambiental ou pelo design de produtos inteiramente novos, chegando ao sistema produto-serviço com ênfase na desmaterialização, que permitirá atingir novos cenários de consumo suficiente, em que propõe-se novos estilos de vida com forte apelo à sustentabilidade. $\mathrm{O}$ avanço nestes níveis, de acordo com Vezzoli (2010) depende primeiramente de o designer aprender a desenvolver produtos e serviços ambientalmente sustentáveis, promovendo assim, novas configurações entre diferentes atores favorecendo o surgimento de soluções inovadoras capazes de convergir para interesses ambientais e econômicos.

Pazmino e Santos (2017), afirmam que a aplicação da abordagem da sustentabilidade no desenvolvimento de produtos faz-se cada vez mais urgente, demandando também uma forma inovadora de ensinar, conduzir e gerar os projetos, que permita que toda a complexidade inerente à sustentabilidade seja atendida. Mas, de acordo com as autoras, a trajetória do design no Brasil não se atentou ao novo paradigma ambiental, sobretudo no âmbito educacional, que tratou o tema com certo descaso nas definições de diretrizes curriculares e elaboração de currículos nos cursos de design, em que disciplinas relacionadas ao meio ambiente e sustentabilidade não são consideradas relevantes.

Para Calegari e Oliveira (2017), verifica-se que a abordagem da sustentabilidade nos cursos de design é realizada em disciplinas específicas ou como afirma Pazmino e Santos (2017), são normalmente oferecidas em fases avançadas, disciplinas complementares ou simplesmente não existem, o que gera, segundo as autoras, um aluno sem contato com a temática, que por sua vez não refletirá sobre suas ações projetuais e decisões tomadas ao longo do projeto, o que potencialmente o fará impactar o meio ambiente a partir da execução dos modelos exigidos pelo curso, protótipos, e no mercado de trabalho. As autoras seguem afirmando que o tema "sustentabilidade" deveria ser pensado de forma interdisciplinar, percorrendo todo o curso de forma transversal, integrando os conteúdos em uma visão mais holística, inovando nos processos metodológicos, o que é exposto também por Calegari e Oliveira (2017), ao afirmar que:

\begin{abstract}
Considera-se relevante que os conceitos de sustentabilidade sejam trabalhados também dentro de outras disciplinas, como as de projeto, em que os estudantes tem a oportunidade de projetar levando em consideração os fatores que minimizem impactos ambientais, sociais e econômicos. Para isso, podem ser utilizadas estratégias de ecodesign, como desenvolvimento de produto voltado para a reciclagem e a reutilização, a redução de materiais, o uso de materiais locais, a escolha por processos de fabricação de baixo custo, e outros que impactem positivamente nas esferas ambiental, social e econômica abordadas na sustentabilidade.
\end{abstract}

Nesta abordagem, é possível aspirar um aluno mais atento às questões ambientais, que leve em consideração, durante todo o curso, aspectos projetuais inerentes a sustentabilidade, o que por sua vez poderá contribuir com a inserção de profissionais mais conscientes no mercado de trabalho e produtos mais coesos com a resiliência ambiental.

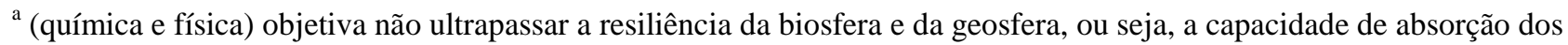
impactos das ações humanas sem provocar um fenômeno irreversível de degradação, em efeitos como o aquecimento global, diminuição da camada de ozônio, acidificação e eutrofização. (VEZZOLI, 2010).
} 
Este artigo, a fim de contribuir com uma abordagem inovadora e transversal do ensino da sustentabilidade nos cursos de design de produto, apresenta um método desenvolvido para a disciplina de Projeto I do curso de design de produto, aplicada em turmas de primeiro período composta por discentes que acabaram de ingressar a universidade. $O$ presente artigo objetiva expor as etapas adotadas para aplicação do método, bem como os resultados alcançados no decorrer da disciplina, a fim de que possa ser replicado em outras instituições de ensino.

\section{Considerações teóricas}

De acordo com Kazazian (2005) não existe um produto totalmente ecológico, já que todos apresentam algum tipo de impacto ao meio ambiente, porém, a idealização de projetos mais sustentáveis implica na redução dos danos ambientais gerados pelo produto durante todo o seu ciclo de vida. Para que isto ocorra, Manzini e Vezzoli (2011) expõem a necessidade de lucidez acerca das etapas envolvidas no processo de produção, que vão desde a obtenção da matériaprima, até o descarte pós-uso. Segundo os autores "podemos contar toda a vida de um produto como um conjunto de atividades e processos, cada um deles absorvendo uma quantidade de matéria e energia", para eles "considerar o ciclo de vida quer dizer adotar uma visão sistêmica de produto, para analisar o conjunto de inputs e dos outputs de todas as suas fases, com a finalidade de avaliar as consequências ambientais, econômicas e sociais".

Para Sampaio et. al (2018), ao se considerar questões de caráter ambiental para a concepção de um novo produto, é possível desenvolver um "produto intrinsecamente mais sustentável", o que pode ser alcançado a partir do conceito de Life Cycle Design (LCD), que consiste na concepção de um novo produto a partir de critérios ambientais, em que, afirma Manzini e Vezzoli (2011), todas as atividades para produção, distribuição, utilização e eliminação/descarte de produto são consideradas como uma só unidade, passando o "projeto do produto" para o "projeto do sistema-produto" em que "[...] a intenção é criar uma ideia sistêmica de produto, em que os inputs de materiais e de energia bem como o impacto de todas as emissões e refugos sejam reduzidos ao mínimo possível, seja em termos quantitativos ou qualitativos, ponderando assim a nocividade de seus efeitos." (IBID, 2002, p.100). Para isto, busca-se a compreensão das seguintes fases:

Quadro 1 - Fases do ciclo de vida

\begin{tabular}{|c|c|}
\hline Fase & Definição \\
\hline $\begin{array}{l}\text { Pré- } \\
\text { produção }\end{array}$ & $\begin{array}{l}\text { Estágio de manuseio das matérias-primas utilizadas para produção dos componentes. } \\
\text { Destacando a aquisição, transporte e transformação dos recursos em materiais e energia; }\end{array}$ \\
\hline Produção & $\begin{array}{l}\text { Estágio onde ocorrem as transformações dos materiais, o processo de montagem e seu } \\
\text { acabamento. Neste ponto, são desenvolvidos a pesquisa a respeito do que se deseja produzir, } \\
\text { seus controles produtivos e o gerenciamento do projeto; }\end{array}$ \\
\hline Distribuição & Estágio que detém a embalagem; o transporte; e a armazenagem do produto; \\
\hline Uso & $\begin{array}{l}\text { Estágio de exercício da funcionalidade do produto, em que, ou ele é utilizado por um intervalo } \\
\text { de tempo ou, obtém sua consumação imediata de acordo com suas características; }\end{array}$ \\
\hline Descarte & Estágio responsável pelo destino final de um produto após o seu período de uso. \\
\hline
\end{tabular}

Fonte: adaptado de Manzini e Vezzoli, 2011 
O conhecimento acerca destas fases permite que o designer consiga projetar o ciclo de vida dos produtos a partir de estratégias que contribuam para o projeto de um produto que seja intrinsecamente mais sustentável. Segundo Manzini e Vezzoli (2011), um designer embasado nestes conhecimentos terá mais êxito para identificar os impactos ambientais dos produtos que está projetando, podendo atenuar com maior precisão os impactos negativos do mesmo ao meio ambiente.

\subsection{Estratégias para o Life Cicle Design}

O estudo conduzido por Manzini e Vezzoli (2011), propõe que para a adoção do Life Cicle Design sejam empregadas uma série de estratégias que auxiliem o designer na tomada de decisão, de maneira que a condução de cada fase do projeto se torne mais coesa. As estratégias, ou linhasguia, estabelecidas pelos autores para a produção de um produto eco eficiente são as seguintes: 1) Minimização dos recursos; 2) Escolha de recursos e processos de baixo impacto ambiental; 3) Otimização da vida dos produtos; 4) Extensão da vida dos materiais; 5) Facilidade de desmontagem. Cada estratégia é seguida de parâmetros, que indicam caminhos para a aplicação do método em projetos de produto. Vale salientar que apenas uma estratégia torna-se insuficiente para atender a todos os requisitos ambientais de um projeto de produto, sendo necessário o estabelecimento de um mix, que garanta melhores resultados.

$\mathrm{Na}$ minimização dos recursos, percebe-se a busca pela redução nas fases de produção, distribuição e durante o período de uso.

Quadro 2 - Minimização dos recursos.

\begin{tabular}{ll}
\hline Estratégias & \multicolumn{2}{c}{ Parâmetros } \\
\hline Minimização o uso de & - Minimizar o conteúdo material de um produto; \\
recursos na produção & - Minimizar as perdas e os refugos; \\
& - Minimizar o consumo de energia para a produção dos produtos; \\
$\begin{array}{l}\text { Minimizar o uso de } \\
\text { recursos na distribuição }\end{array}$ & - Minimizar o consumo de recursos no desenvolvimento dos produtos; \\
$\begin{array}{l}\text { Minimizar o consumo de } \\
\text { recursos durante o uso }\end{array}$ & - Minimizar os consumos para o transporte; \\
\hline
\end{tabular}

Fonte: adaptado de Manzini e Vezzoli, 2011, p.118-134

$\mathrm{Na}$ escolha de recursos e processos de baixo impacto ambiental, são abordadas tecnologias de transformação e de beneficiamento dos materiais, considerado-se a etapa de distribuição dos produtos.

Quadro 3 - escolha de recursos e processos de baixo impacto

\begin{tabular}{ll}
\hline Estratégias & Parâmetros \\
\hline $\begin{array}{l}\text { A escolha dos materiais } \\
\text { e dos processos de baixo } \\
\text { impacto }\end{array}$ & $\begin{array}{l}\text { - Devem ser considerados os processos de produção e de transformação de matérias, os } \\
\text { sistemas de distribuição e uso, e os tratamentos de eliminação final dos produtos; }\end{array}$ \\
$\begin{array}{l}\text { A escolha de recursos } \\
\text { energéticos de baixo }\end{array}$ & $\begin{array}{l}\text { - Avaliar quais fontes energéticas disponíveis fornecerão menor impacto ambiental, em } \\
\text { impacto }\end{array}$ \\
& $\begin{array}{l}\text { todo o ciclo de vida do produto; } \\
\text { de gerar bem-estar para o ecossistema; }\end{array}$ \\
\hline
\end{tabular}

Fonte: adaptado de Manzini e Vezzoli, 2011, p.148-180

As estratégias para otimização da vida dos produtos consideram a medida do tempo de 
vida de um produto e seus materiais, a partir da conservação de seu rendimento.

Quadro 4 - As estratégias para otimização da vida dos produtos

\begin{tabular}{|c|c|}
\hline Estratégias & Parâmetros \\
\hline $\begin{array}{l}\text { Projetar a duração } \\
\text { adequada }\end{array}$ & $\begin{array}{l}\text { - } \quad \text { Projetar a vida útil do produto de acordo com a das suas partes; } \\
\text { - } \quad \text { durojetar a vida útil das partes de acordo com a duração prevista para substituí-los } \\
\text { - Optar por materiais duráveis tendo em vista a necessidade e a vida útil do produto; } \\
\text { - } \quad \text { Evitar materiais permanentes para funções temporárias; }\end{array}$ \\
\hline Projetar a segurança & $\begin{array}{l}\text { - } \quad \text { Minimizar o número de partes e componentes; } \\
\text { - } \quad \text { Simplificar os produtos; } \\
\text { - } \quad \text { Evitar junções frágeis na composição do produto como um todo; }\end{array}$ \\
\hline $\begin{array}{l}\text { Facilitar a atualização } \\
\text { e a adaptabilidade }\end{array}$ & $\begin{array}{l}\text { - Permitir a atualização das partes do produto como um todo; } \\
\text { - Projetar produtos permutáveis, modulares e reconfiguráveis, em áreas de dimensão, } \\
\text { serventia e estética; }\end{array}$ \\
\hline $\begin{array}{l}\text { Facilitar a } \\
\text { manutenção }\end{array}$ & $\begin{array}{l}\text { - } \quad \text { Facilitar a substituição das partes que necessitem de manutenção periódica, } \\
\text { - } \quad \text { Pimplificando o acesso e remoção; } \\
\text { - } \quad \text { Prover e facilitar a substituição dos componentes de forma mais ágil; } \\
\text { - } \quad \text { Projetar fácil manutenção no próprio ambiente de uso; } \\
\text { - } \quad \text { Projetar procurando reduzir as operações de manutenção; }\end{array}$ \\
\hline $\begin{array}{l}\text { Facilitar a reparação } \\
\text { e a reutilização }\end{array}$ & $\begin{array}{l}\text { - } \quad \text { Predispor e facilitar e facilitar a remoção e retorno das partes do produto que estão } \\
\text { - } \quad \text { Pujeitas a danos; } \\
\text { - } \quad \text { Projetar partes e componentes padronizados; } \\
\text { - } \quad \text { Projetar a reutilização de partes auxiliares; } \\
\text { - } \quad \text { Incrementar a reutilização de partes mais sujeitas a avarias e rupturas; } \\
\text { - } \quad \text { Projetar prevendo um segundo uso; }\end{array}$ \\
\hline $\begin{array}{l}\text { Facilitar a } \\
\text { remodelação }\end{array}$ & $\begin{array}{l}\text { - Projetar a viabilidade da remoção, substituição e a permuta das partes e dos } \\
\text { componentes dentro de uma mesma linha de produtos; }\end{array}$ \\
\hline $\begin{array}{l}\text { Intensificar a } \\
\text { reutilização }\end{array}$ & $\begin{array}{l}\text { - } \quad \text { Projetar produtos/serviços voltados ao uso compartilhado; } \\
\text { - } \quad \text { Projetar produtos/serviços voltados para o uso coletivo; } \\
\text { - } \quad \text { Projetar produtos com funções integradas; } \\
\text { - } \quad \text { Projetar produtos multifuncionais com componentes comuns e substituíveis; }\end{array}$ \\
\hline
\end{tabular}

Fonte: adaptado de Manzini e Vezzoli, 2011, p.188-208

As estratégias para a extensão da vida dos materiais relacionam-se a transformação de matérias primas em secundárias e na incineração para uso de seu conteúdo energético.

Quadro 5 - As estratégias para a extensão da vida dos materiais

\begin{tabular}{ll}
\hline Estratégias & Parâmetros \\
\hline $\begin{array}{l}\text { Adotar a reciclagem } \\
\text { em efeito cascata }\end{array}$ & $\begin{array}{l}\text { Planejar e projetar o uso dos materiais reciclados de forma que estes sejam aplicados de } \\
\text { maneira sequencial em produtos de qualidades cada vez mais inferiores até à exaustão } \\
\text { da qualidade do material; }\end{array}$
\end{tabular}

Escolher materiais - Optar por materiais de fácil recuperação as características das suas serventias iniciais; com tecnologias de - Evitar o uso de materiais compostos, preferindo aqueles compatíveis com uma 
reciclagem eficiente

Facilitar a recolha e o transporte após o uso

Identificar os materiais

Minimizar o número de materiais compatíveis entre si

Facilitar a limpeza

Facilitar a compostagem

Facilitar a combustão tecnologia de reciclagem mais eficiente;

- Optar preferencialmente por polímeros termoplásticos, substituindo os termorrígidos;

- Projetar considerando a relação entre o produto e o material a ser utilizado;

- Evitar aditivos, utilizando termoplásticos resistentes às temperaturas de uso;

- $\quad$ Devem ser avaliadas todas as possibilidades tecnológicas e econômicas;

- Projetar em relação ao sistema de recuperação dos produtos eliminados;

- Minimizar o peso do produto;

- Minimizar o volume e tornar compactáveis os produtos eliminados;

- Informar ao usuário informações sobre o modo de descarte do produto;

- Codificar vários materiais para definir o seu tipo;

- $\quad$ Fornecer informações complementares sobre a ideia do material;

- Posicionar os códigos em lugares visíveis;

- $\quad$ Fornecer informações complementares sobre a idade do material, número de reciclagens já efetuadas e os aditivos utilizados;

- Integrar as funções das partes de um material, reduzindo o número de componentes e de materiais empregados;

- $\quad$ Utilizar em um mesmo produto materiais que sejam compatíveis entre si;

- Os materiais devem ser limpos para eliminar as contaminações adquiridas pelo contato com outros componentes ou derivadas de operações de tratamento de superfícies;

- $\quad$ Os tipos de produtos que se adaptam a este tipo de tratamento são caracterizados por um alto percentual de materiais putrescíveis, ou seja, indicados à compostagem;

- É útil proceder à incineração de um material somente após este ter sido reciclado e reutilizado várias vezes.

Fonte: adaptado de Manzini e Vezzoli, 2011, p.222-240

Para a estratégia de facilitação da desmontagem, aborda-se o conceito de Design for Disassembly (DFD), que consiste em conceber e projetar produtos facilitando a sua desmontagem.

Quadro 6 - Facilitando a desmontagem

\begin{tabular}{|c|c|}
\hline Estratégias & Parâmetros \\
\hline $\begin{array}{l}\text { Minimizar e facilitar as } \\
\text { operações para a } \\
\text { desmontagem e separação }\end{array}$ & $\begin{array}{l}\text { - Ao considerar a estrutura das conexões de um produto, é investigada a } \\
\text { possibilidade de substituição de um componente sem que seja necessário o } \\
\text { desmonte de outros ou ter de efetuar outras desmontagens paralelas; }\end{array}$ \\
\hline $\begin{array}{l}\text { Usar sistemas com junções } \\
\text { reversíveis }\end{array}$ & Este princípio tem por finalidade estender a vida de um produto; \\
\hline $\begin{array}{l}\text { Usar sistemas de união } \\
\text { permanente que possam } \\
\text { ser facilmente abertos }\end{array}$ & $\begin{array}{l}\text { - É levado em consideração a sua aplicação e seu uso, a afim de reduzir o grau de } \\
\text { impacto causado ao componente para que seu dano para o reaproveitamento } \\
\text { seja o menor possível; }\end{array}$ \\
\hline $\begin{array}{l}\text { Prever tecnologias e } \\
\text { formas específicas para a } \\
\text { desmontagem destrutiva }\end{array}$ & $\begin{array}{l}\text { - É um método eficiente quando se deseja uma rápida separação de alguns } \\
\text { materiais ou no caso de eliminar insertos incompatíveis com o material utilizado }\end{array}$ \\
\hline $\begin{array}{l}\text { Minimizar o número de } \\
\text { materiais incompatíveis } \\
\text { entre si }\end{array}$ & $\begin{array}{l}\text { - Integrar as funções das partes de um material, reduzindo o número de } \\
\text { componentes e de materiais empregados; } \\
\text { - Utilizar em um mesmo produto materiais que sejam compatíveis entre si; }\end{array}$ \\
\hline
\end{tabular}


Usar materiais facilmente separáveis quando

triturados
- É necessário conhecer as tecnologias necessárias para a separação desses materiais;

- É necessário que os insertos incompatíveis sejam facilmente removidos dos materiais que são reciclados através de tecnologias eficientes;

Fonte: adaptado de Manzini e Vezzoli, 2011, p.254-267

\section{Considerações metodológicas}

A sustentabilidade é um conteúdo que se arrasta desde o ensino fundamental até a universidade, cuja temática é abordada apenas em Feiras de Ciências ou em eventos comemorativos que fazem alusão a Semana do Meio Ambiente. Esse afastamento da responsabilidade ambiental propicia a formação de indivíduos incapazes de visualizar os benefícios presentes na preservação do meio ambiente, tratando com descaso questões sobre o desperdício dos recursos naturais, a poluição e a destruição dos ambientes terrestres e aquáticos.

Nas universidades está percepção se agrava a partir da inexistência de conteúdos e disciplinas que levem os discentes a questionar o seu papel no contexto ambiental, salvo em alguns casos como disciplinas conhecidas como Ciências do Ambiente.

No Curso de Design da Universidade Federal de Campina Grande/PB, o referido conteúdo é ministrado em disciplinas optativas (Design e Ecologia e Design e Desenvolvimento) que só podem ser cursadas a partir do 6으o período. Quando o aluno se encontra praticamente no final do curso. Mostrando total descaso com a temática. Todavia, para amenizar essa situação e promover no início do curso de graduação a reflexão sobre a relação do design e as consequências ambientais resultante do desenvolvimento de produtos, foi proposto que na disciplina PROJETO 1 (primeiro período), fosse abordado em um de seus estágios, o ecodesign e o design sustentável, visando despertar nos alunos o uso da capacidade criativa, pertinente a profissão de designer, na concepção de produtos que levem em consideração os requisitos ambientais apresentados por Manzini e Vezzoli (2011).

\section{A disciplina foi dividida em três estágios:}

No 1 o estágio foram elaborados exercícios na forma de desafios, que tinham como objetivo principal apresentar ao aluno as potencialidades dos materiais e a suas limitações de uso na atividade projetual. Os desafios eram iniciados e finalizados em sala de aula, sendo utilizado um cronômetro para o controle do tempo de execução da tarefa. Ao final da aula havia uma discussão referente aos resultados obtidos onde aspectos de produção, desperdício, reutilização, construção, modularidade, etc eram identificados e evidenciados para reflexão. Na Figura 1 são apresentados dois exemplos de desafios iniciais: a) criar uma estrutura mais alta possível com o uso de uma folha $A 3(75 \mathrm{~g})$ e 50 centímetros de fita adesiva e b) criar uma estrutura que suporte o peso de tijolos com o uso do mesmo material. Esses dois exercícios apresentavam o uso do material em duas situações bem distintas, descontruindo a percepção sobre a fragilidade do papel. Vale salientar que as atividades eram em grupo, o que promovia a integração entre os alunos recém-chegados ao curso. 
Figura - 1: Estruturas confeccionadas com uma folha $A 3(75 \mathrm{~g})$ e $50 \mathrm{~cm}$ de fita adesiva
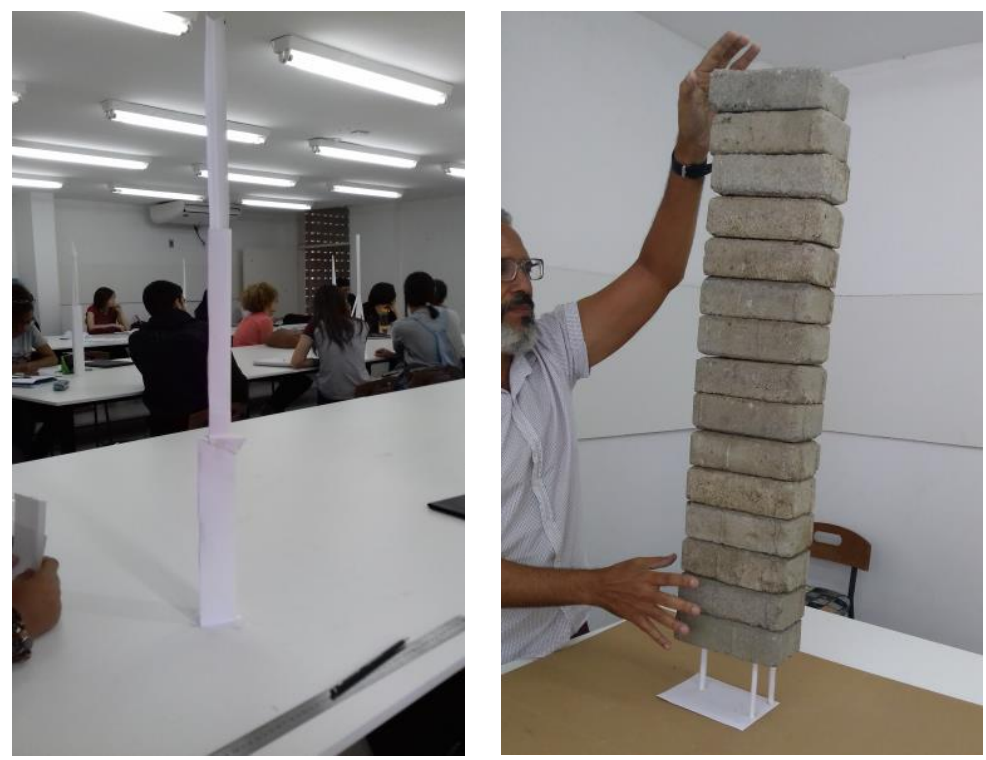

Fonte: autores (2018)

O 2을 estágio teve como foco a análise dos sistemas funcionais existentes nos produtos, destacando as partes e componentes, formas de união, travamento, extensão, etc. Buscando sempre detalhar como os elementos se relacionam para executar determinada função. Neste estágio os alunos desmontavam produtos existentes, identificavam e classificavam os sistemas funcionais e criavam sistemas de transferência e transformação de movimentos (Figura 2), passando os mesmos a entender como os produtos são construídos, estruturados, montados e desmontados.

Figura - 2: Sistemas funcionais de transferência de movimento
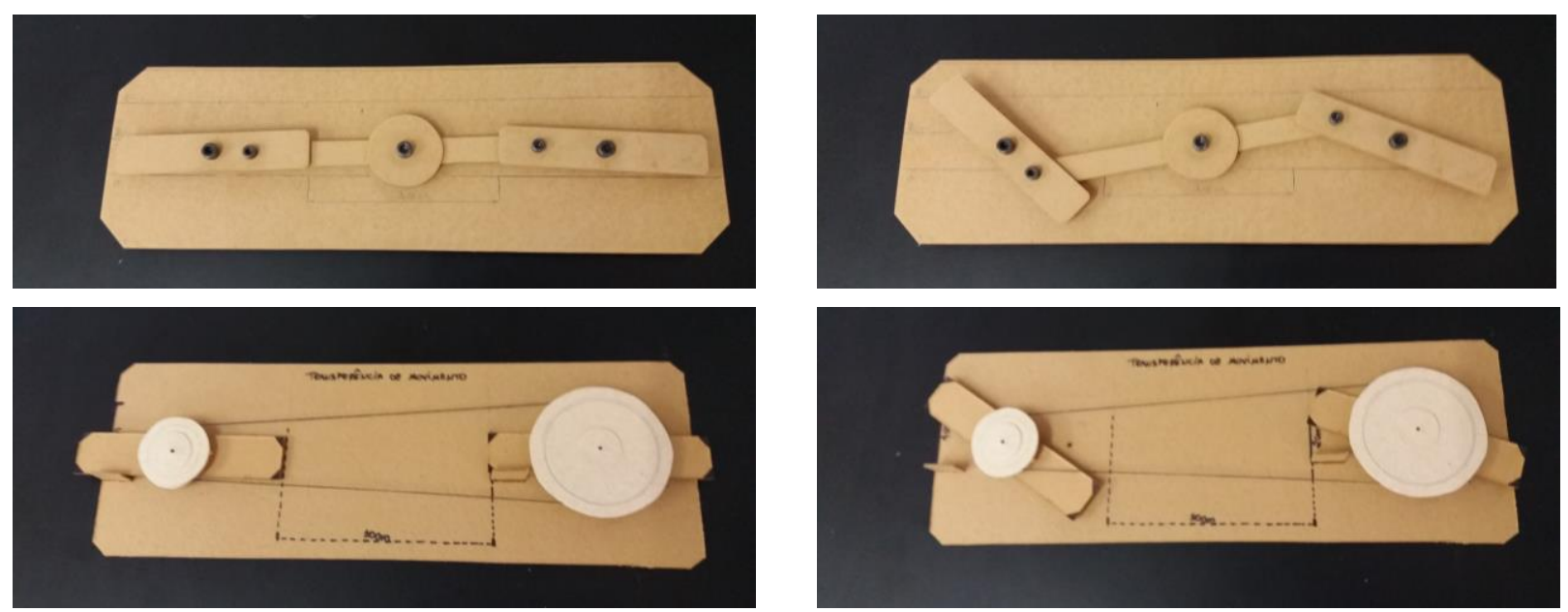

Fonte: autores (2018)

Estas duas etapas da disciplina tinham como função preparar o aluno para o estágio seguinte, onde cada grupo seria responsável pelo desenvolvimento de um produto com as seguintes características:

- Confeccionado em papelão corrugado e tubo de papelão;

- Montagem ser toda por encaixe; 
- O produto deveria vir desmontado e sua montagem seria realizada apenas na hora da apresentação;

- Não poderia ser utilizado nenhum material para colar, fixar ou unir. Sendo permitido apenas o uso de fita crepe para dar acabamento ao produto.

Antes da fase de desenvolvimento do produto houve uma apresentação em PowerPoint falando sobre ecodesign e design sustentável. Foi explicado como seria o 3 을 Estágio e a turma foi dividida em grupos. Após discussão sobre 3 proposituras projetuais apresentadas pelos grupos, o professor passou a redirecionar os projetos a serem executados, visando alcançar o maior número de requisitos descritos por Manzini e Vezzoli. Tais como:

Do Life Cicle Design se buscou: a) minimização dos recursos, programando a redução do uso de materiais e de energia; b) trabalhar com o mínimo de desperdício, criando um plano de corte e a utilização de partes padronizadas que se repetem; e c) facilidade de desmontagem, permitindo a separação das partes e componentes e a necessidade de encaixes intuitivos e fáceis de serem executados.

Do quadro Minimização dos Recursos teve-se a seguinte orientação: sempre que possível, reduzir o conteúdo de material de um produto simplificando sua forma e seus sistemas. Neste sentido menos é mais. Evitar perdas e refugos, sendo que partes retiradas e consideradas descartes podem compor um sistema ou ser incorporado na estrutura.

Do quadro As estratégias para otimização da vida dos produtos obteve-se o seguinte desdobramento: Reduzir as partes e componentes para haver uma simplificação da forma evitando o surgimento de junções frágeis na composição do produto como um todo. Prover e facilitar a substituição dos componentes de forma mais ágil, através de sistemas de encaixe sem uso de cola. Projetar partes e componentes padronizados que permitam sua replicação, redução no tempo de confecção e maior controle de qualidade e substituição de partes, se necessário.

Do quadro As estratégias para a extensão da vida dos materiais foi estabelecido: o uso do papelão corrugado na forma de placas ou tubos, pois são facilmente reciclados. Não utilizar tinta, cola ou outros materiais que por ventura possam retirar o aspecto sustentável do produto. Projetar considerando a relação entre o produto e o material a ser utilizado, haja vista que por suas características físicas e químicas deva-se evitar o contato direto com alimentos.

E por fim, do quadro Facilitando a desmontagem foi direcionado: facilitar as operações para desmontagem e separação das partes, facilitando a substituição de seus componentes; integrar as funções das partes.

\section{Resultados}

A atividade de concepção e desenvolvimento dos produtos foi realizada basicamente em sala de aula com supervisão contínua do professor. Foram realizados desenhos esquemáticos, sketchs e pequenos mockups para testar a viabilidade de construção da estrutura final.

Como exemplos do resultado da disciplina são apresentados quatro projetos a seguir: 
Figura 3 - Mesa de estudos para criança
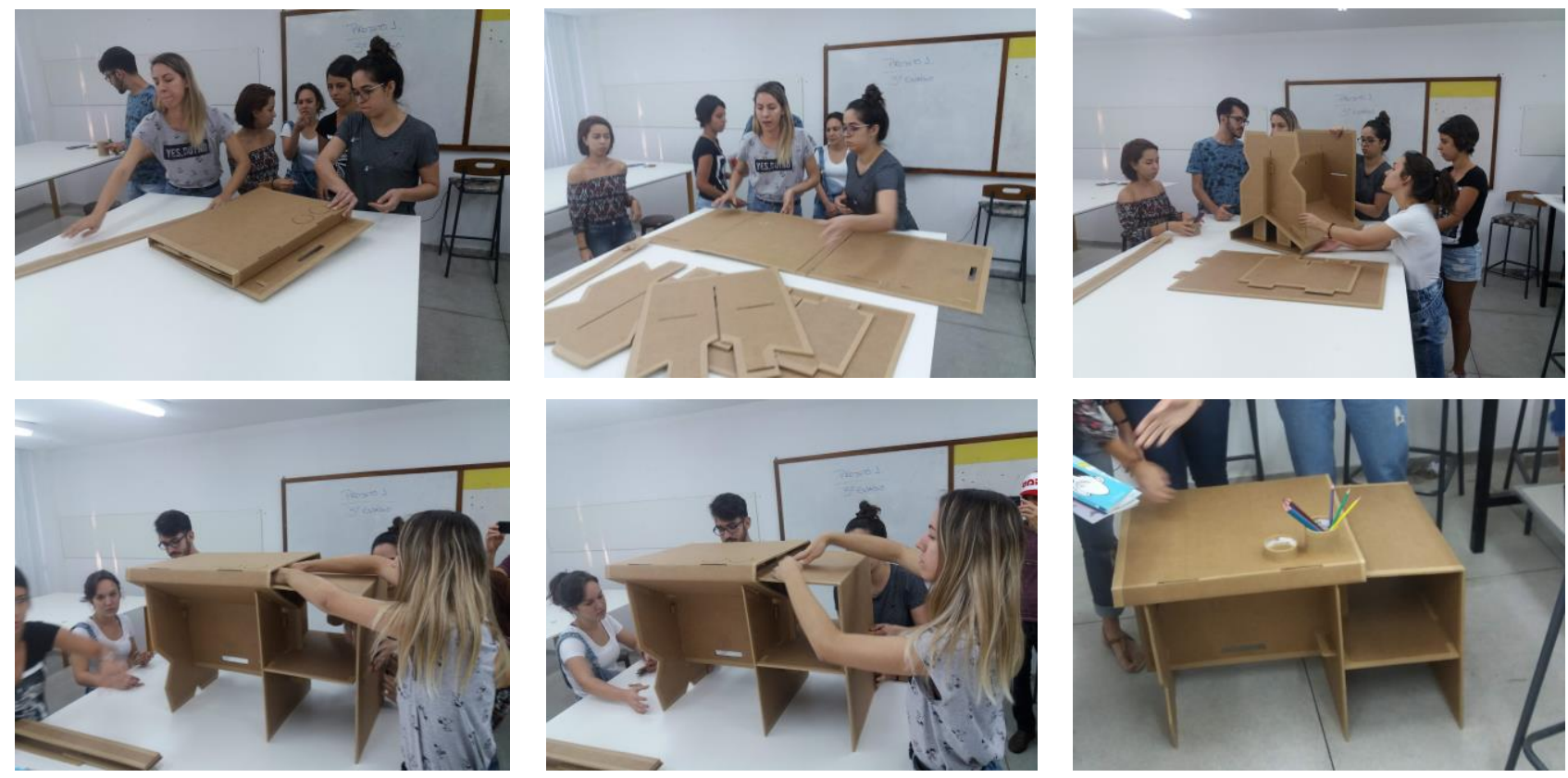

Fonte: autores (2018)

Destaca-se a compactação da estrutura que é apresentada na forma de uma maleta facilitando o transporte, o armazenamento e a proteção das peças a serem utilizadas na montagem do produto. Peças padronizadas, combinação no uso de placas e tubos de papelão e simplificação no sistema de montagem.

Figura 4 - Suporte para apoio e balanço de bebê conforto
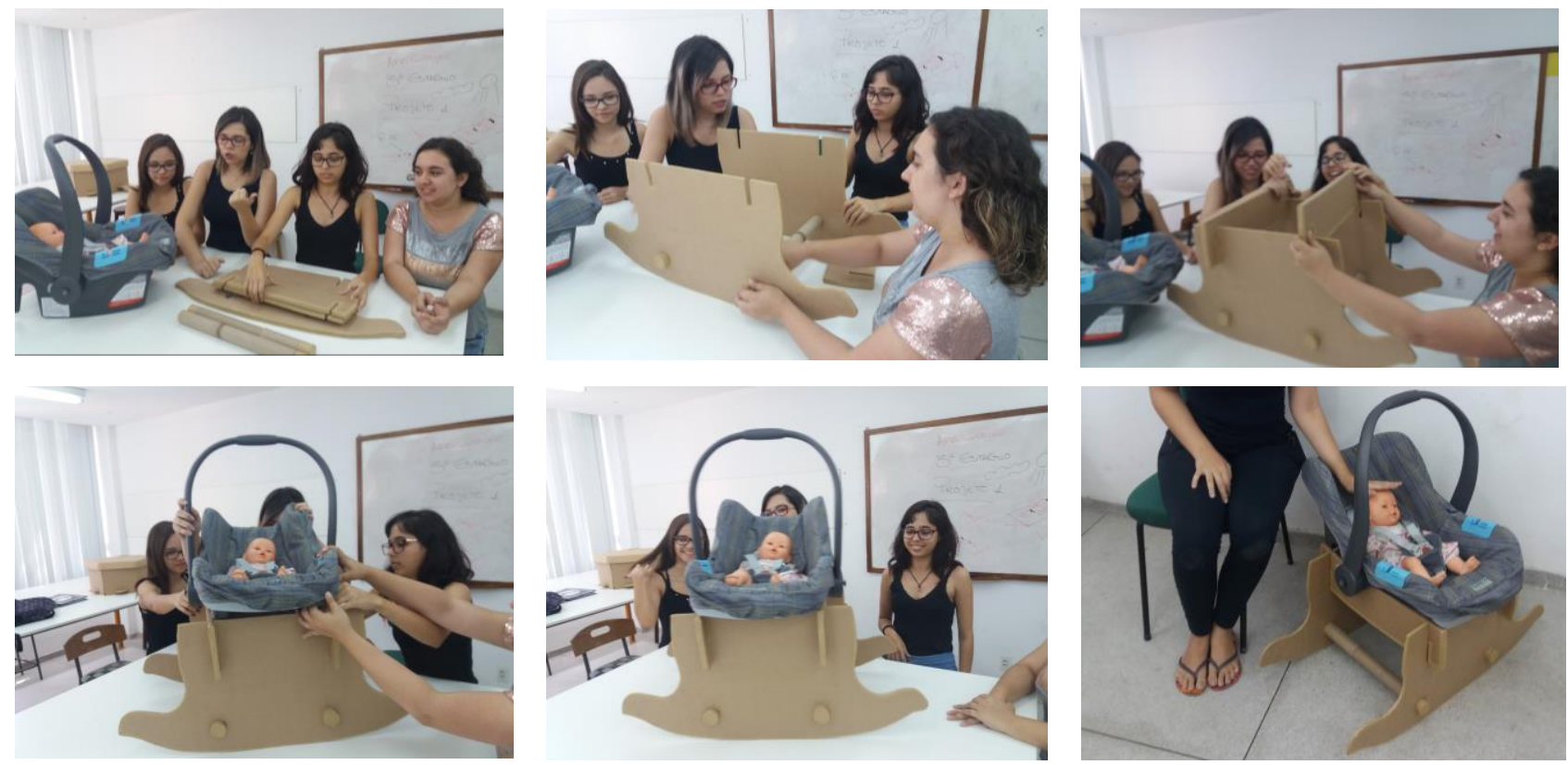

Fonte: autores (2018)

Neste produto destaca-se a simplicidade formal e visual. Composição com poucas partes. Uso de um sistema de encaixe eficiente, que permite rápida montagem, desmontagem e a substituição de peças danificadas. Uso do tubo de papelão para dar maior estabilidade ao produto. 
Figura 5 - Expositor de plantas do tipo cactáceas
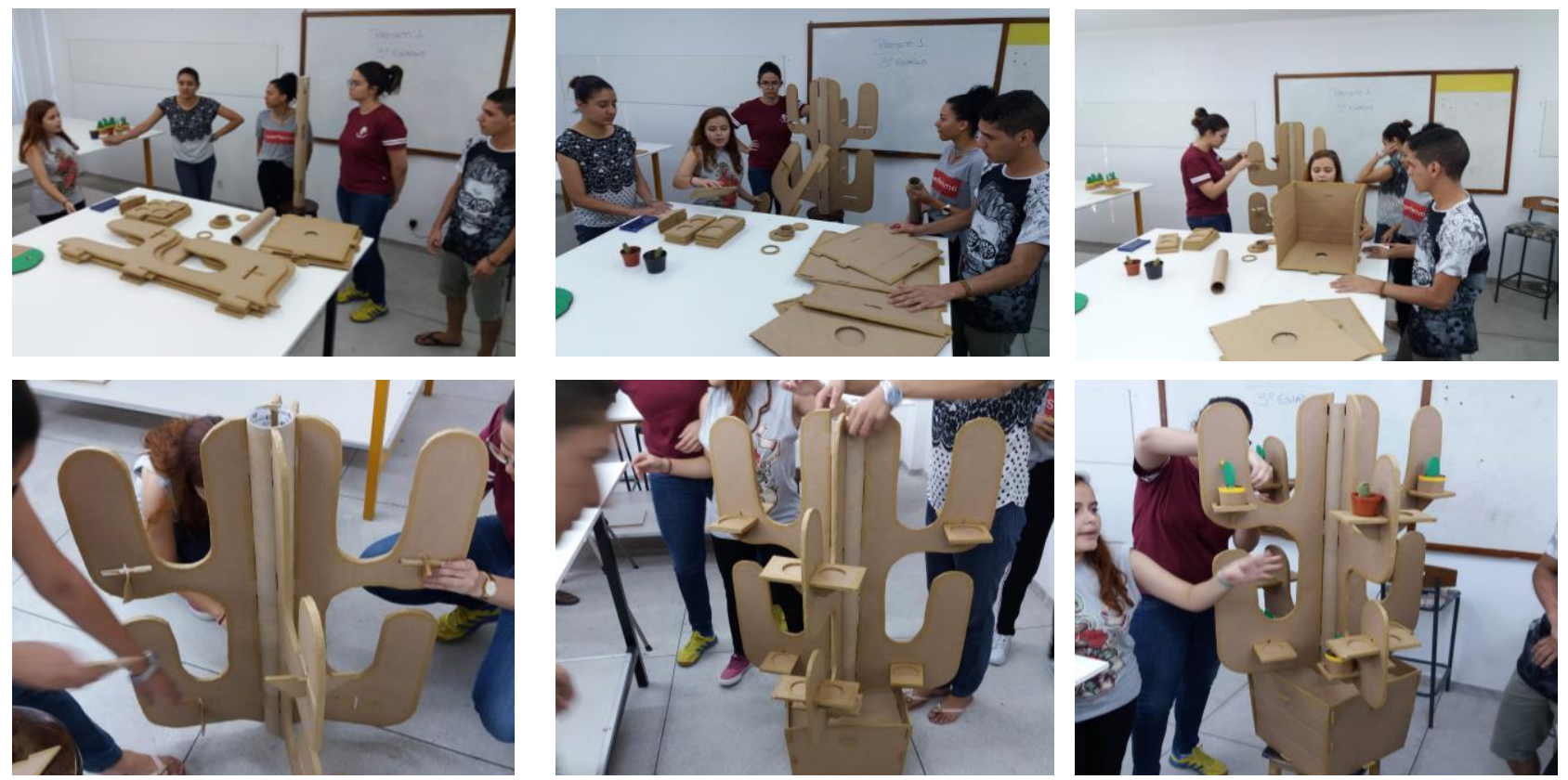

Fonte: autores (2018)

Neste produto destaca-se a repetição dos módulos. A composição em duas partes principais possibilitando a divisão da atividade de montagem e a redução do tempo de execução. O uso do descarte de corte das peças maiores para concepção dos componentes menores.

Figura 6 - Viveiro para passarinhos
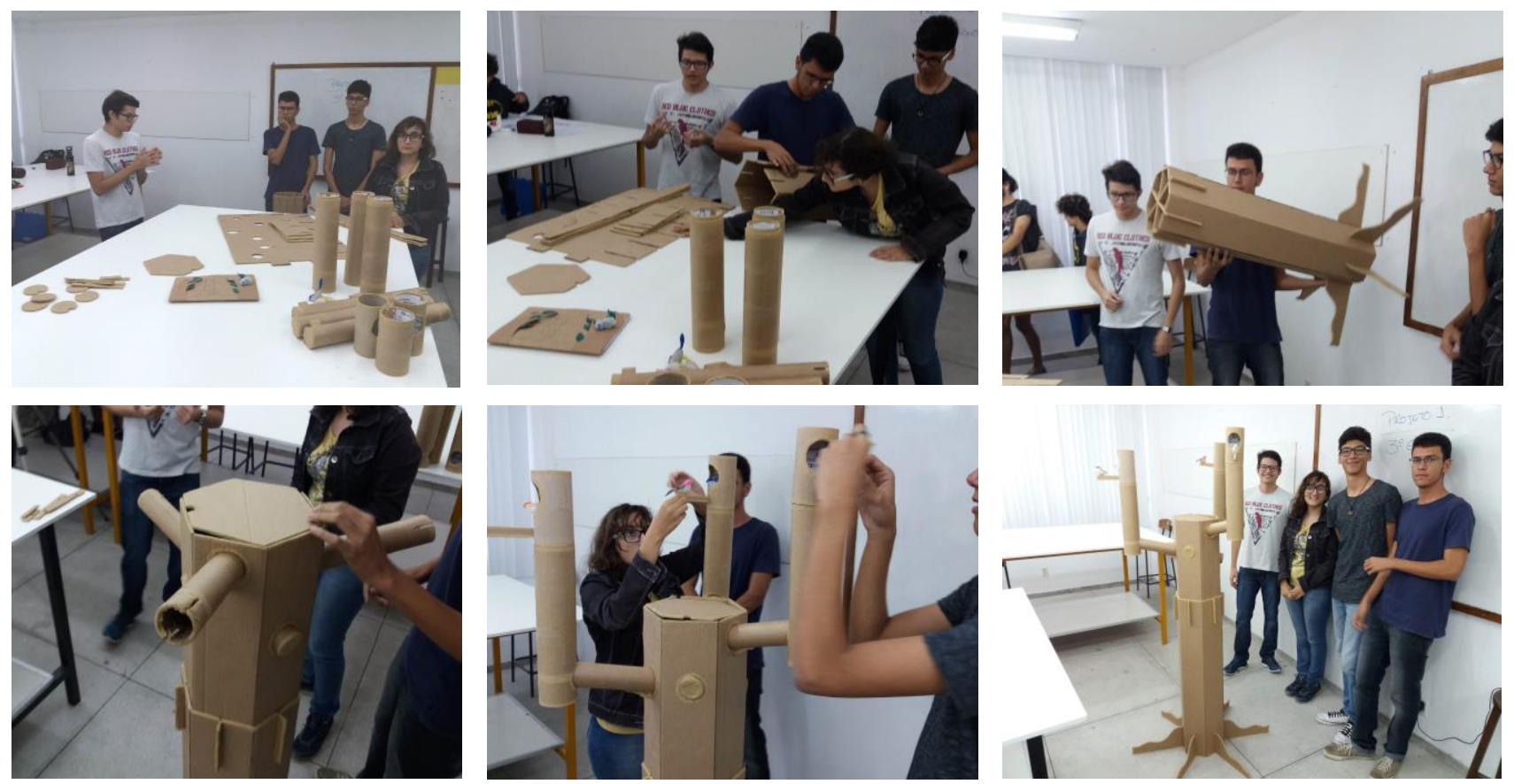

Fonte: autores (2018)

Verifica-se o uso de conexões e encaixes bem elaborados. A forma hexagonal da estrutura vertical simplifica o processo de construção dando estabilidade ao produto. A parte superior onde fica o ninho do passarinho pode ser retirada para limpeza ou sua total substituição. 


\section{Considerações finais}

Com relação aos desafios do 1 을 estágio foi verificada a dificuldade dos alunos lidarem com recursos limitados de materiais e o controle do tempo para a realização das atividades. No $2 \stackrel{0}{2}$ estágio foi identificada a falta de entendimento de como os elementos estruturais e funcionais de um produto se relacionam para alcançar determinado objetivo como fechar, travar, equilibrar, unir, etc. Já no 3o estágio, o maior problema foi o preconceito sobre o material utilizado (papelão corrugado) que para muitos era considerado de baixo valor e inadequado ao uso. Todavia, após as apresentações, em uma discussão final, os alunos relataram como ponto positivo a inovação no processo metodológico, que abordou a sustentabilidade de forma sequencial, culminando em um produto ecologicamente correto, promovendo uma visão diferenciada sobre a profissão do designer, principalmente em relação ao uso de materiais e processos de produção. Evidenciando assim, o início de uma mudança de comportamento em prol das questões ambientais.

A preparação dos alunos em relação às propriedades dos materiais, suas limitações físicas e o entendimento de sistemas funcionais, auxiliou a execução do produto final. Com relação às práticas sustentáveis apresentadas por Manzini e Vezzoli, constata-se que cada projeto conseguiu contemplar um mix de requisitos apropriados para sua realidade, tais como, compactação da estrutura, utilização de módulos, sistemas de encaixes simples e eficientes, padronização das peças, combinação de elementos (tubos e placas) com o mesmo material, montagem e substituição de partes de forma facilitada e reutilização de resíduos. Por esses motivos, verificouse que foi alcançado o objetivo de incluir sustentabilidade na fase inicial da graduação.

A adoção de aspectos sustentáveis em disciplinas de projeto assume um papel de conscientização da importância da prática do designer na concepção e materialização de produtos ecologicamente orientados. Contudo existe a necessidade de se continuar a reflexão sobre a sustentabilidade nas outras disciplinas do curso, para fomentar uma mudança significativa no comportamento dos futuros profissionais.

\section{Referências}

CALEGARI, Eliana Paula; OLIVEIRA, Branca Freitas de. A sustentabilidade no ensino de design em instituições federais de ensino superior no Brasil. Mix sustentável (impresso), v.3, n.1, p. 109-118, 2017

KAZAZIAN, Thierry. Haverá a idade das coisas leves: design e desenvolvimento sustentável. 2 ed. São Paulo: Editora Senac são Paulo, 2009. 193 p

MANZINI, Ezio. Design para a inovação social e sustentabilidade: comunidades criativas, organizações colaborativas e novas redes projetuais. Rio de Janeiro: E-papers, 2008. 104 p.

MANZINI, Ezio; VEZZOLI, Carlo. O desenvolvimento de Produtos Sustentáveis: os requisitos ambientais dos produtos industriais. 1 ed. São Paulo: Editora da Universidade de São Paulo, 2011. $366 \mathrm{p}$.

PAZMINO, Ana Veronica; SANTOS, Adriane Shibata. Design e sustentabilidade: necessidade de quebra de paradigma no ensino. Mix sustentável (impresso), v.3, n.1, p. 10-16, 2017.

SANTOS, Aguinaldo dos; LOPES, Camila S. D; SAMPAIO, Claudio P; TREIN, Fabiano A; CHAVES, Liliane; Lisiane, LIBRELOTTO; FERROLI, Paulo Cesar; LEPRE, Priscila; ENGLER, suzana; Martins, Viviane. Design para a sustentabilidade: dimensão ambiental. Curitiba: Insight, 2018. 183 p.

VEZZOLI, Carlo. Design de sistemas para a sustentabilidade. 1 ed. Salvador: EDUFBA, 2010. 342 p. 